\title{
The Research of Disaster Preparation Program and Quick Recovery Program in the Gas Station Management System
}

\author{
Wendong Wang* \\ Petro China Company Limited, Guizhou Sales Branch, Guizhou, 550081 \\ ${ }^{*}$ Corresponding author
}

\begin{abstract}
With the continuous development of information construction in modern enterprise, the business information system was integrated and the operating activities were more and more dependent on the core data of it. The gas station management system, which was called MS, as a basic application system in the oil-sale activity of the petroleum sales companies was just the relevant information source that we need. The loss was un-estimable when the MS was breakdown in the disaster accident which would led to the stored data lost. This paper was the research of disaster preparation program and quick recovery program with the example of the application, which would be helpful for the ability improvement of the resist-risk and disaster as well as the reduction of the loss.
\end{abstract}

Keywords-disaster preparation program; quick recovery program; application example research

\section{THE PROJECT IMPLEMENTATION BACKGROUND}

A. The Necessity of Implementation of Disaster Preparation Program and Quick Recovery Program

At present, there were some problems in the MS need to be solved such as, the backup strategy was immature and imperfect in dealing with disaster failures, and there was no method in dealing with systematic destruction.

\section{B. The Importance of Implementation of Disaster}

Preparation Program and Quick Recovery Program

With the increasing reliance on the MS in the operating activities, disaster preparation program and quick recovery program would be a guarantee for daily business and the market competitive power would be enhanced.

\section{THE IMPLEMENTATION OF DISASTER PREPARATION PROGRAM AND QUICK RECOVERY PROGRAM}

\section{A. Implementation Purpose}

Disaster preparation program and quick recovery program were put into effect under limited costs and resources, which would balance costs and risks while establishing backup strategy and shortening recovery time, as well as reducing the loss of systematic failure and disaster destruction.

\section{B. Implementation Principles}

Disaster preparation program and quick recovery program were put into effect under those circumstances, such as lower influence on daily business, balance of cost and benefit, making full use of existing equipment, easy to use and operate, and so on.

\section{Implementation Development}

\section{1) Scheme architecture}

There were two components in disaster preparation program and quick recovery program, the part one of which was servicer-side to store the critical data for oil-sale stations, and the part two of which was client-side to store the operating data for every oil-sale station. The scheme architecture was showed in Fig.1.

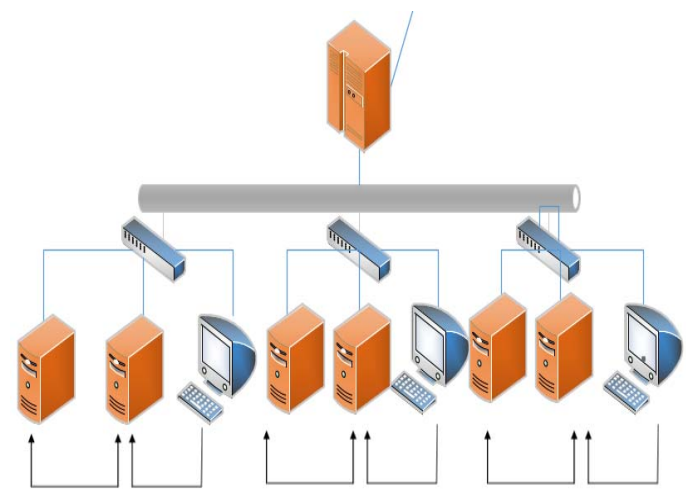

FIGURE I SCHEME ARCHITECTURE

2) The project implementation technical support

Linux was chosen as the OS, which was the safest OS in the world. The raid 5 disk array and 5 pieces of $2 \mathrm{~T}$ capacity hard disk were installed in servicer-side, as well as Symantec Netbackup Master was chosen as the backup strategy software in order to store the critical data. Symantec Netbackup Client called NBU was chosen as the software in order to store and transfer the critical data up to servicer-side, while Symantec System Recovery called SSR was chosen as the software in order to make U disk, which was the OS tool of boot up and A-key recovery for oil-sale stations.

3) The project implementation backup strategy

a. Disaster strategy classification

According to the amount and the storage location of backup data, it was divided into 6 types, which were full backup, incremental backup, differential backup, on-demand backup, local backup and remote backup. 


\section{b. The OS of oil-sale stations backup strategy}

The local D disk was chosen as back-up-disk. BOS and FUEL would back up the OS to each other's D disk by local networks. The daily backup was operated at 4 am every day and the full backup was operated every week, while the differential backup was operated on remaining dates of the same week. There were 3 recovery points and the oldest recovery point would be deleted when the latest recovery points turned up. On the other side, there was storage threshold for the back-up disk and the oldest recovery point would be also deleted when the back-up disk overflowing. The local D disk was chosen as back-up-disk for POS as well, which was operated by local networks from POS to FUEL. The on-demand backup was operated for POS, and the full backup would be operated when POS was installed or the application was some upgraded or new upgraded.

\section{c. The critical data of oil-sale stations backup strategy}

The critical data of oil-sale stations backup called remote backup was operated from client-side to service-side at 0 am every day. In a regular situation, the critical data of oil-sale stations was saved within 2 weeks only and would be cleared up then.

\section{d. The disaster recovery strategy}

There were 4 methods for disaster recovery. When the backup disk was not damaged, the U disk was chosen to boot up and A-key recovery the OS, and the disaster recovery was operated after preset. When the backup was damaged, the U disk was chosen to launch the network service by IP and A-key recovery the OS through back-up-disk for POS which was local D disk of FUEL, and the disaster recovery was operated after preset. When BOS could be logged in normally while the data was damaged, NBU was chosen to back up the recently one day data to the specified path through the network. When natural disasters occurred or computer virus invaded and the data was damaged, NBU was chosen to back up the recently time data to the specified computer and the critical data of oil-sale stations could be back up while OS and application software were reinstall.

\section{THE PROJECT IMPLEMENTATION RESULTS}

There were 4 results through installation testing which were showed as follows.

\section{A. Low Influence on the Daily Business}

The commonly used back-up software called Ghost would cost 10 minutes, however, it must restart the computer which would interrupted continuous production. On the contrary, the new project would back up OS online at 4 am every day which would little affect the daily business of oil-sale stations.

\section{B. Quick Back-up Speed and Less Storage Space}

It would take SSR very little time and very little storage space to back up OS, except that the full backup would be operated at the first installation and the differential backup would be operated at the remaining dates of the same week, while the oldest back-up data would be deleted automatically when the back-up disk overflowing. The back-up time statistic of an oil-sale station was showed in Tab.1.
TABle I. The BACK-UP Time Statistic OF AN OIL-SALE Station

\begin{tabular}{ccccc}
\hline Oil-sale-Station & Equipment & $\begin{array}{c}\text { OS } \\
\text { Disk } \\
\text { Size }\end{array}$ & $\begin{array}{c}\text { Back-up } \\
\text { Data } \\
\text { Size/G }\end{array}$ & $\begin{array}{c}\text { Back-up } \\
\text { Time }\end{array}$ \\
\hline Jin Yang & BOS & 33 & 17.2 & $11^{\prime} 27^{\prime \prime}$ \\
\hline Jin Yang & FUEL & 34 & 14.3 & 8' \\
\hline Jin Yang & POS & 53 & 18.5 & $22^{\prime} 4^{\prime \prime}$ \\
\hline
\end{tabular}

\section{Quick OS Recovery Speed}

The OS recovery time was little and the operation was simple in for oil-sale stations because that the $U$ disk was chosen to root up and A-key recovery the OS. The OS recovery time statistic of an Oil-sale station was showed in Tab.2.

TABLE II. THE RECOVERY TIME STATISTIC OF AN OIL-SALE STATION

\begin{tabular}{cccc}
\hline $\begin{array}{c}\text { Oil-sale } \\
\text { Station }\end{array}$ & Equipment & $\begin{array}{c}\text { OS Disk } \\
\text { Size/G }\end{array}$ & $\begin{array}{c}\text { OS Recovery } \\
\text { Time }\end{array}$ \\
\hline Jin Yang & POS & 22 & 12 '38”, \\
\hline Jin Yang & BOS & 34 & 8'55”, \\
\hline Jin Yang & FUEL & 34 & $99^{\prime 2} 6^{\prime \prime}$ \\
\hline
\end{tabular}

The critical data back-up time was only 4 minutes when the data size was 2.53G and was recovered from servicer-side to specified computer, while the time was about 50 minutes when the same data was recovered to the BOS through $4 \mathrm{M}$ broadband network. The comparison of OS recovery time between traditional method and the disaster recovery program was showed in Tab.3.

TABLE III. THE COMPARISON OF OS RECOVERY TIME BETWEEN TRADitional METHOD AND THE DISASTER RECOVERY PROGRAM

\begin{tabular}{|c|c|c|c|c|}
\hline $\begin{array}{c}\text { Fault } \\
\text { Condition }\end{array}$ & \multicolumn{2}{|c|}{ Traditional Method } & \multicolumn{2}{|c|}{$\begin{array}{c}\text { The Disaster Recovery } \\
\text { Program }\end{array}$} \\
\hline $\begin{array}{l}\text { Backup } \\
\text { Disk } \\
\text { Normal }\end{array}$ & $\begin{array}{c}\text { Theoretical } \\
\text { Minimum } \\
\text { Time }\end{array}$ & $\begin{array}{c}4-7 \\
\text { hours }\end{array}$ & $\begin{array}{c}\text { Theoretical } \\
\text { Minimum } \\
\text { Time }\end{array}$ & $\begin{array}{l}10-30 \\
\text { minutes }\end{array}$ \\
\hline $\begin{array}{l}\text { Backup } \\
\text { Disk } \\
\text { Damaged }\end{array}$ & $\begin{array}{c}\text { Theoretical } \\
\text { Minimum } \\
\text { Time }\end{array}$ & $\begin{array}{l}28-78 \\
\text { hours }\end{array}$ & $\begin{array}{c}\text { Theoretical } \\
\text { Minimum } \\
\text { Time }\end{array}$ & 3-7 hours \\
\hline $\begin{array}{c}\text { BOS } \\
\text { Damaged } \\
\text { \& No Data }\end{array}$ & $\begin{array}{c}\text { Theoretical } \\
\text { Minimum } \\
\text { Time }\end{array}$ & $\begin{array}{l}29-55 \\
\text { hours }\end{array}$ & $\begin{array}{c}\text { Theoretical } \\
\text { Minimum } \\
\text { Time }\end{array}$ & $\begin{array}{l}8-10 \\
\text { hours }\end{array}$ \\
\hline
\end{tabular}


D. Lower Cost Input Than Loss of Continuous Production Interruption

The cost input of disaster preparation program and quick recovery program were server, backup software and $U$ disk with no additional hardware added. Although the project could not be used to recovered the MS when the disaster accident come out, however, the project cost input was lower which was in line with the cost-benefit principle and the interrupt time was acceptably short, as well as there was no over-protection phenomenon or under-protection phenomenon in the implementation.

\section{REFERENCES}

[1] Xijian Liu. IT Management in CNPC [M]. Petroleum Industry Press. 2008.

[2] Xijian Liu. Enterprise Informatization Practice Guide [M]. Petroleum Industry Press. 2011. 